\title{
Urban-Rural Differences in the Trends of Type I and Type 2 Diabetes Among Adults Who Received Medical Treatment from Public Hospitals in Resource-Poor Community Tigray, Ethiopia
}

This article was published in the following Dove Press journal:

Diabetes, Metabolic Syndrome and Obesity: Targets and Therapy

\author{
Getachew Gebremedhin (iD) 1,2 \\ Fikre Enqueselassie ${ }^{2}$ \\ Negussie Deyessa ${ }^{2}$ \\ Helen Yifter ${ }^{3}$ \\ 'College of Medicine and Health \\ Sciences, Department of Nursing, Adigrat \\ University, Adigrat, Ethiopia; ${ }^{2}$ College \\ Health Sciences, School of Public Health, \\ Addis Ababa University, Addis Ababa, \\ Ethiopia; ${ }^{3}$ College Health Sciences, \\ School of Medicine, Addis Ababa \\ University, Addis Ababa, Ethiopia
}

${ }^{\dagger}$ Fikre Enqueselassie passed away on October 28, 2019

\begin{abstract}
Objective: This study carried out to describe urban-rural differences in the trend of type 1 and type 2 diabetes among adults who have received medical treatment from public hospitals over the last five years.
\end{abstract}

Methods: The trends of adult diabetes assessed from September 1, 2013, to August 31, 2018, using hospital-based retrospective medical records of 299,806 adult patients in the adult medical outpatient and emergency units. Data were collected using a uniform data abstraction format. An extended Mantel-Haenszel chi-square test of the linear trend used to examine the trend over time.

Results: Of the total 299,806 adult patients, 3056 (1.02\% (95\% CI: 0.98-1.06)) patients were confirmed diabetes patients. The overall trend in the proportion of diabetes had increased from 6.8 to 14.3 per 1000 adult patients. The trend of type 1 diabetes increased for both urban from 1.0 to 2.2 per 1000 adult urban residents and rural from 1.2 to 2.6 per 1000 adult rural residents, with statistically a significant increase $\left(\chi^{2}=9.1, \mathrm{P}=0.002\right)$ and $\left(\chi^{2}=17.8, \mathrm{P}<0.001\right)$ for linear trend, respectively. The trend of type 2 diabetes increased for both urban from 6.9 to 14.0 per 1000 adult urban residents and rural from 4.0 to 9.5 per 1000 adult rural residents, with a statistically significant increase $\left(\chi^{2}=68.4\right.$, $\mathrm{P}<0.001)$ and $\left(\chi^{2}=74.2, \mathrm{P}<0.001\right)$ for linear trend, respectively. The higher increase in the proportion of both type 1 and type 2 diabetes observed among women patients.

Conclusion: The trend in the proportion of type 1 and type 2 diabetes increasing for both urban and rural residents, with a higher increase observed among women. These findings highlight health-care professionals and policymakers to design effective public health policies to treat each type of disease.

Keywords: urban, rural, trend, type 1 diabetes, type 2 diabetes

\section{Introduction}

Diabetes is one of the most epidemic diseases of this century. The global size of diabetes has grown from 108 million in 1980 to 425 million in 2017, and this could be reached 693 million by 2045 and varies by age, gender and residence. ${ }^{1,2}$ In the modern era, diabetes has no border that imposes unacceptably high human, social, and economic costs on countries at all income levels worldwide. In 2015, roughly 5 million people aged 20 to 79 years died from diabetes-related deaths, which is equivalent to one death every six seconds, and about $14.5 \%$ of the global all-cause mortality among adults. ${ }^{1-3}$
Correspondence: Getachew

Gebremedhin

Email guchosole786@gmail.com 
Acute and long-term diabetes complications bring about substantial economic loss by increased use of health services, loss of productivity, disability, and premature death. As a result, diabetes imposes the economic burden on individuals, families, national health systems and the economy of a country. ${ }^{1,2,4}$

Even though incidence rates of diabetes are decreasing in the developed countries in the previous two decades such as in the United States (US) and Switzerland; ${ }^{4,5}$ still, it is alarmingly increasing in low and middle-income countries (LMICs) such as China, India, and Brazil. ${ }^{6-8}$ In 2017 , about $80 \%$ of people with diabetes live in LMICs, since these countries were on rapid economic and societal transitions. ${ }^{1,9-11}$

Ethiopia is the leading country in Sub-Saharan Africa (SSA), with over 2.6 million adult diabetes patients; with an estimated diabetes prevalence of $5.2 \%$ in $2017,{ }^{1,3}$ probably catalyzed by economic and societal transitions, and childhood malnutrition, with about $70 \%$ of adults with undiagnosed diabetes. ${ }^{1,10,12}$ Recent studies in Ethiopia ${ }^{13-15}$ indicated that more than one-third of patients admitted with hyperglycemic emergencies were undiagnosed diabetes, which suggests people die undiagnosed and the prevalence of diabetes could be beyond this magnitude.

Studies indicated that type 1 diabetes (T1D) and type 2 diabetes (T2D) are the two major public health concerns types of diabetes elsewhere in the world, including Ethiopia. ${ }^{16,17}$ Even though both type 1 and type 2 diabetes results in hyperglycemia, pathophysiology, and etiology of the diseases are distinct and require us to consider each type of diabetes independently. ${ }^{18}$ Study in the US suggested that type 1 and type 2 diabetes accounted for about $6 \%$ and $91 \%$ of all cases of diagnosed diabetes, respectively. ${ }^{19}$ Recent studies in Italy and Ethiopia indicated, type 1 diabetes is strongly associated with poverty and markers of undernutrition, most marked in the rural cases and excess among men compared to women. ${ }^{17,20}$ The trend on the prevalence of T2D is alarmingly increased over time in developing countries, including SSA countries due to marked economic and epidemiologic transitions, which result in altering lifestyle practices, and marked increases in overweight and obesity. ${ }^{6,21}$

Studies indicate that both type 1 and type 2 diabetes have become an increasingly prevalent, problematic and severe public health issue for both urban and rural residents, with the highest prevalence in urban areas. ${ }^{6,22,23}$ Studies in Ethiopia, Myanmar, India, and Peru showed the prevalence of diabetes is higher for urban dwellers compared to rural residents. ${ }^{6,24-26}$ Location of residence is also important in terms of access to care and health outcomes; people living in rural areas have increased treatment gaps and acute complications with their diabetes. $^{1,2,27}$

Sex-related differences in lifestyle may lead to differences in the risk of developing diabetes mellitus and, in consequence, to differences in the prevalence of this condition in women and men. ${ }^{27,28}$ Studies in the US, Italy, and Ethiopia indicate that male participants had a higher risk than female study participants in all age-groups for both type 1 and type 2 diabetes. ${ }^{17,19,20}$ But other studies in SSA countries suggested that the prevalence of diabetes is higher among women compared to men; this is due to higher rates of obesity among women, ${ }^{29,30}$ or history of gestational diabetes mellitus, which is associated with an increased risk of subsequent $\mathrm{T} 2 \mathrm{D}$ in mothers and their offspring. ${ }^{11,28}$

Although diabetes brings real economic loss by increased use of health services, loss of productivity, disability and premature death in the developing nations including Ethiopia, robust data on adult diabetes are scarce in Ethiopia as well in Tigray; where most clinical data are not timely assessed and made accessible for policy and decision-makers. This study demonstrated the trend in the proportion of adult T1D and T2D for both urban and rural residents, which will have a crucial input in shifting healthcare priorities for policymakers and planners for planning health services for the needy and preventing premature adult deaths.

\section{Methods and Materials Study Period and Population}

The study was conducted in seven public hospitals of Tigray in northern Ethiopia among adult patients aged 18 years and above, who received medical treatment from adult medical outpatient and emergency units from September 1, 2013, to August 31, 2018.

\section{Study Design and Data Collection}

This study was a hospital-based retrospective record review of patients registered in the study period and units. All five years' medical records of adult patients aged 18 years and above who received medical treatment were included in the review and screened from the registry log book. But adult patients with gestational diabetes and diabetes patients with referral papers were excluded from the study to decrease over enumeration of cases. 
Data abstracted using a uniform data abstraction format prepared to gather relevant data from the medical records both paper copy file and e file/smart care/after the data abstraction format pretested from 295,806 adult patients. Nursing and public health experts recruited for data abstraction. Data collectors and supervisors were trained for one day on how to retrieve, abstract relevant data from the medical records, and keep records back in the original location. The data abstraction format pretested in 300 adult medical records two weeks before the actual data abstraction period for fitness and consistency.

\section{Operational Definitions}

New diabetes case: Physician diagnosed as a diabetes patient for the first time with fasting blood sugar (FBS) $\geq 126 \mathrm{mg} / \mathrm{dL}$, or repeated random blood sugar (RBS) $\geq 200$ $\mathrm{mg} / \mathrm{dL}$ plus fatigue, polyuria, polydipsia, and other symptoms, we considered a new diabetes patient. ${ }^{1,2}$

Type 1 diabetes: When the patient presented with FBS $\geq 126 \mathrm{mg} / \mathrm{dL}$ or RBS $\geq 200 \mathrm{mg} / \mathrm{dL}$ plus classic symptoms excessive urination, excessive thirst, unexplained weight loss, and increased hunger, we considered as type 1 diabetes patient. $^{2}$

Type 2 diabetes: When the patient presented with FBS $\geq 126 \mathrm{mg} / \mathrm{dL}$ or RBS $\geq 200 \mathrm{mg} / \mathrm{dL}$ plus other symptoms such as excess body weight, physical inactivity, unhealthy diet, and family history of diabetes, we considered as T2D patient. $^{2}$

\section{Data Analysis}

Data entered in Epi data manager 4.3 for Windows 10 software and analyzed using SPSS Version 25.0 software, and we used a list-wise deletion for missing variables to have a complete case analysis across time. The key covariate of interest was the time (in years), which allowed the estimation of change in the prevalence of type 1 and type 2 diabetes over time. We calculated Mean and Standard Deviation (SD), and proportions for continuous variables and categorical variables, respectively. Extended Mantel-Haenzel chi-square test for linear trends used to examine trends in diabetes proportion for the period September 1, 2013, to August 31, 2018, using Epi info 7.1.5 STAT CALC, and the trends of both type 1 and type 2 diabetes observed by residence and gender. A p-value of $<0.05$, considered statistically significant for the linear trend, and findings presented in text, table, and figures.

\section{Ethical Statement}

The ethical statement protocol approved by the Institution Review Board (IRB) of Addis Ababa University-College of Health Sciences (AAU-CHS), and waiver letter obtained. In addition, a written permit obtained from the Tigray Regional State Health Bureau and respective hospitals' administrative bodies after submitting the protocol and explaining the purpose of the study. For the sake of privacy and confidentiality, no personal identifiers, such as names, were collected.

\section{Results}

Out of the total 299,806 adult patients who received medical care services in the studied hospitals, 128,915 (43.0\%) of the patients were women, and 126,559 (42.2\%) of them were rural residents. From those patients who received medical treatment, 3056 (10.2 per 1000 adult patients) were confirmed, diabetes patients. The proportion of diabetes was 11.6 per 1000 urban residents, and 8.6 per 1000 rural residents. The mean $( \pm \mathrm{SD})$ age of adult diabetes patients at diagnosis was $46.04( \pm 14.96)$ years, with $26.41( \pm 9.45)$, and $49.65( \pm 12.98)$ years, for Type 1 diabetes (T1D) and Type 2 diabetes (T2D), respectively. Of the total of 3056 newly diagnosed adult diabetes patients, $1705(55.8 \%)$ were men and 2011 (66\%) of the diabetes patients were urban residents. Four hundred eighty-seven $(15.9 \%)$ of adult diabetes patients, were type 1 diabetes patients and half of these were rural residents. Of the total 2569 T2D patients, 1768 (68.8\%) were urban residents. Almost one-third of the diabetes patients treated at Ayder comprehensive specialized hospital (ACSH) (Table 1). Supporting information available (PPTX) in Tables S1 and $\mathrm{S} 2$.

The overall trend of diabetes had increased from 6.8 to 14.3 per 1000 adult patients, with increased for both urban (7.9 to 15.9 per 1000 adult urban residents) and rural (from 5.2 to 13.2 per 1000 adult rural residents) in the observation period (Figure 1). Supporting information available in Tables S1 and S2.

The trend of diabetes had a higher increase in those ages group 60 and above years, with 15.5 per 1000 adult patients compared to those in the age group of 18 to 29 years with 6.8 per 1000 adult patients in the observation period (Figure 2). Supporting information available in Table S3.

The overall proportion of Type 1 diabetes was $0.16 \%$ (95\% CI: $0.15-0.18)$, with a statistically significant 
Table I Characteristics of Newly Diagnosed Adult Diabetes Patients in Selected Public Hospitals of Tigray, Ethiopia (September I, 2013 to 2018, August 31, 2018)

\begin{tabular}{|c|c|c|}
\hline Patient Characteristics & Frequency & Percent \\
\hline \multicolumn{3}{|l|}{ Gender } \\
\hline Men & 1705 & 55.8 \\
\hline Women & $135 \mid$ & 44.2 \\
\hline \multicolumn{3}{|l|}{ Residence } \\
\hline Urban & 2011 & 65.8 \\
\hline Rural & 1045 & 34.2 \\
\hline \multicolumn{3}{|l|}{ Age } \\
\hline$<29$ & 466 & 15.3 \\
\hline 30 to 39 & 561 & 18.4 \\
\hline 40 to 49 & 750 & 24.5 \\
\hline 50 to 59 & 617 & 20.2 \\
\hline 60 Years and above & 662 & 21.7 \\
\hline \multicolumn{3}{|l|}{ Type of diabetes } \\
\hline Type I diabetes & 487 & 15.9 \\
\hline Type 2 diabetes & 2569 & 84.1 \\
\hline \multicolumn{3}{|l|}{ Type I Diabetes } \\
\hline Urban resident & 243 & 49.1 \\
\hline Rural residents & 244 & 50.1 \\
\hline \multicolumn{3}{|l|}{ Type 2 Diabetes } \\
\hline Urban residents & 1768 & 68.8 \\
\hline Rural residents & 801 & 31.2 \\
\hline \multicolumn{3}{|l|}{ Hospital Diabetes Treated } \\
\hline Ayder comprehensive specialized hospital & 944 & 30.9 \\
\hline Mekelle hospital & 465 & 15.2 \\
\hline Ma'ychew Lemlem karl hospital & 408 & 13.4 \\
\hline Adigrat hospital & 332 & 10.9 \\
\hline St Merry hospital & 376 & 12.3 \\
\hline Suhul shire hospital & 326 & 10.7 \\
\hline Abyi Adi hospital & 205 & 6.7 \\
\hline
\end{tabular}

increase $\left(\chi^{2}=34.5, \mathrm{P}<0.001\right)$ for linear trend. The proportion of T1D for both urban and rural residents was $0.14 \%$ (95\% CI: $0.12-0.16)$ and $0.19 \%$ (95\% CI: 0.17-0.22), with a statistically significant increase $\left(\chi^{2}=9.1, \mathrm{P}=0.002\right)$ and $\left(\chi^{2}=17.8, \mathrm{P}<0.001\right)$ for linear trend, respectively. The proportion of T1D for women was $0.17 \% \quad(95 \% \mathrm{CI}$ : $0.12-0.16)$, with statistically significant increase $\left(\chi^{2}=20.2, \mathrm{P}<0.001\right)$ for linear trend, but not for men $\left(\chi^{2}=\right.$ $3.1, \mathrm{P}=0.08$ ) (Table 2).

The overall trend of type 1 diabetes had increased from 1.1 to 2.4 per 1000 adult patients, with the trend of type 1 diabetes increased for both urban (1.0 to 2.2 per 1000 adult urban residents) and rural (from 1.2 to 2.6 per 1000 adult rural residents) in the observation period (Figure 3 ).

The overall proportion of T2D was $0.86 \%(95 \% \mathrm{CI}$ : 0.82-0.89), with statistically significant increase $\left(\chi^{2}=151.0, \mathrm{P}<0.001\right)$ for linear trend. The proportion of T2D for both urban and rural residents was 1.0\% $(95 \%$ CI: $0.97-1.10)$ and $0.63 \%$ (95\% CI: 0.59-0.68), with statistically significant increase $\left(\chi^{2}=68.4, \mathrm{P}<0.001\right)$ and $\left(\chi^{2}=74.2, \quad \mathrm{P}<0.001\right)$ for linear trend, respectively. The proportion of $\mathrm{T} 2 \mathrm{D}$ for both men and women was $0.84 \%$ (95\% CI: $0.79-0.88$ ) and $0.88 \%$ (95\% CI: $0.83-0.94)$, with statistically significant increase $\left(\chi^{2}=32.0, \mathrm{P}<0.001\right)$ and $\left(\chi^{2}=70.3, \mathrm{P}<0.001\right)$ for linear trend, respectively (Table 3).

The overall trend of T2D has increased from 5.7 to 12.0 per 1000 adult patients, with increased for both urban (6.9 to 14.0 per 1000 adult urban residents) and rural (from 4.0 to 9.5 per 1000 adult rural residents) in the observation period (Figure 4).

\section{Discussion}

The present study used a retrospective record administrative health care data from hospital logbook and patient charts to investigate urban-rural differences in the trend of type 1 and type 2 diabetes among adult patients in resource-poor community Tigray between September 1, 2013, and August 31, 2018. The proportion of diabetes in this study was 10.2 per 1000 adult patients, with 11.6 per 1000 urban residents and 8.6 per 1000 rural residents with age. The trend in the proportion of adult diabetes steadily increased with time in

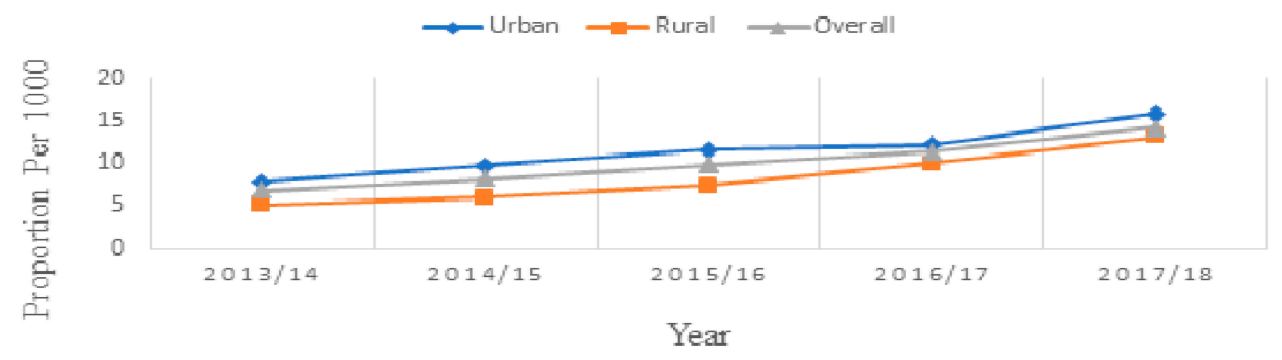

Figure I The overall trends in the proportion of diabetes by residence in the selected public hospitals of Tigray, Ethiopia (September I, 20I3 to August 3 I, 20I8). 


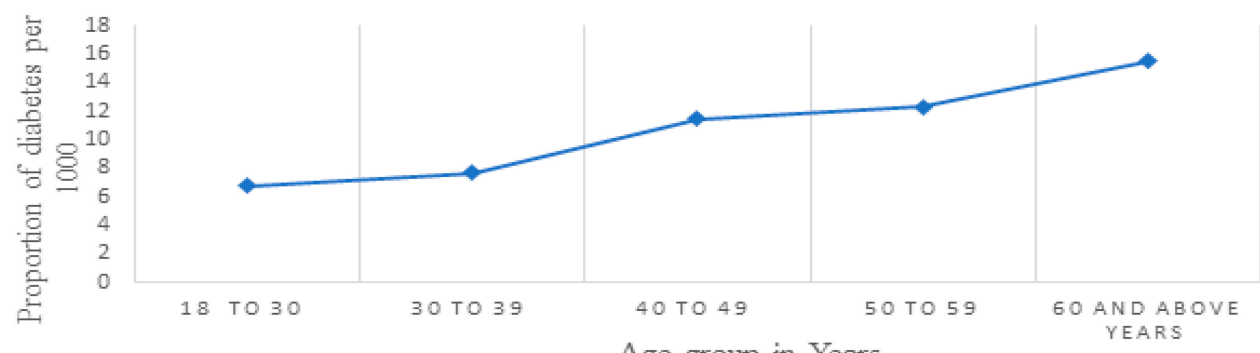

Age group in Years

Figure 2 Trends in the proportion of diabetes by age category per 1000 adult patients in the selected public hospitals of Tigray, Ethiopia (September I, 20I 3 to August 31 , 2018).

both urban and rural residents for both T1D and T2D, and for both men and women patients in the observation period.
The finding of this study suggests, the trend in the proportion of adult diabetes has definitely risen more than double over the last five-years observation period,

Table 2 The Trends of TID by Residence and Gender (Extended Mantel-Haenszel Chi-Square and Proportion) in the Selected Hospitals of Tigray, Ethiopia (September, 2013 to August, 2018)

\begin{tabular}{|c|c|c|c|c|c|c|}
\hline Variable & Year & $\begin{array}{l}\text { DM } \\
\text { Patients }\end{array}$ & $\begin{array}{l}\text { OPD } \\
\text { Patients }\end{array}$ & $\begin{array}{l}\text { Proportion of DM } \\
\text { (\%) }\end{array}$ & $95 \% \mathrm{Cl}$ & MH-OR \\
\hline Overall Proportion of TID & $\begin{array}{l}2013 / 14 \\
2014 / 15 \\
2015 / 16 \\
2016 / 17 \\
2017 / 18 \\
\text { Total }\end{array}$ & $\begin{array}{l}59 \\
76 \\
91 \\
109 \\
152 \\
487\end{array}$ & $\begin{array}{l}55,734 \\
58,806 \\
60,221 \\
61,805 \\
63,240 \\
299,806\end{array}$ & $\begin{array}{l}0.11 \\
0.13 \\
0.15 \\
0.18 \\
0.24 \\
0.16\end{array}$ & $\begin{array}{l}{[0.08-0.14]} \\
{[0.10-0.16]} \\
{[0.12-0.19]} \\
{[0.14-0.21]} \\
{[0.21-0.28]} \\
{[0.15-0.18]}\end{array}$ & $\begin{array}{l}1.000 \\
1.221 \\
1.428 \\
1.667 \\
2.274 \\
\chi^{2}=34.5, \quad P<0.001\end{array}$ \\
\hline $\begin{array}{l}\text { Proportion of TID Among Urban } \\
\text { Residents }\end{array}$ & $\begin{array}{l}2013 / 14 \\
2014 / 15 \\
2015 / 16 \\
2016 / 17 \\
2017 / 18 \\
\text { Total }\end{array}$ & $\begin{array}{l}31 \\
42 \\
45 \\
44 \\
81 \\
243\end{array}$ & $\begin{array}{l}31,914 \\
34,370 \\
34,645 \\
36,244 \\
36,074 \\
173,247\end{array}$ & $\begin{array}{l}0.10 \\
0.12 \\
0.13 \\
0.12 \\
0.22 \\
0.14\end{array}$ & $\begin{array}{l}{[0.07-0.14]} \\
{[0.09-0.16]} \\
{[0.10-0.17]} \\
{[0.09-0.16]} \\
{[0.18-0.28]} \\
{[0.12-0.16]}\end{array}$ & $\begin{array}{l}1.000 \\
1.254 \\
1.334 \\
1.250 \\
2.315 \\
\chi^{2}=9.1, P=0.002\end{array}$ \\
\hline $\begin{array}{l}\text { Proportion of TID Among Rural } \\
\text { Residents }\end{array}$ & $\begin{array}{l}2013 / 14 \\
2014 / 15 \\
2015 / 16 \\
2016 / 17 \\
2017 / 18 \\
\text { Total }\end{array}$ & $\begin{array}{l}28 \\
34 \\
46 \\
65 \\
71 \\
244\end{array}$ & $\begin{array}{l}23,820 \\
24,436 \\
25,576 \\
25,56 \mid \\
27,166 \\
126,559\end{array}$ & $\begin{array}{l}0.12 \\
0.14 \\
0.18 \\
0.25 \\
0.26 \\
0.19\end{array}$ & $\begin{array}{l}{[0.08-0.17]} \\
{[0.10-0.19]} \\
{[0.13-0.24]} \\
{[0.20-0.32]} \\
{[0.21-0.33]} \\
{[0.17-0.22]}\end{array}$ & $\begin{array}{l}1.000 \\
1.188 \\
1.536 \\
2.173 \\
2.233 \\
\chi^{2}=17.8, P<0.001\end{array}$ \\
\hline Proportion of TID Among Men & $\begin{array}{l}2013 / 14 \\
2014 / 15 \\
2015 / 16 \\
2016 / 17 \\
2017 / 18 \\
\text { Total }\end{array}$ & $\begin{array}{l}39 \\
39 \\
45 \\
63 \\
77 \\
263\end{array}$ & $\begin{array}{l}31,312 \\
34,273 \\
34,267 \\
36,579 \\
34,460 \\
170,891\end{array}$ & $\begin{array}{l}0.12 \\
0.11 \\
0.13 \\
0.17 \\
0.22 \\
0.15\end{array}$ & $\begin{array}{l}{[0.09-0.17]} \\
{[0.08-0.16]} \\
{[0.10-0.18]} \\
{[0.13-0.22]} \\
{[0.18-0.28]} \\
{[0.14-0.17]}\end{array}$ & $\begin{array}{l}1.00 \\
0.914 \\
1.054 \\
1.383 \\
1.796 \\
\chi^{2}=3.1, P=0.08\end{array}$ \\
\hline Proportion of TID Among Women & $\begin{array}{l}2013 / 14 \\
2014 / 15 \\
2015 / 16 \\
2016 / 17 \\
2017 / 18 \\
\text { Total }\end{array}$ & $\begin{array}{l}20 \\
37 \\
46 \\
46 \\
75 \\
224\end{array}$ & $\begin{array}{l}24,422 \\
24,533 \\
25,952 \\
25,226 \\
28,780 \\
128,915\end{array}$ & $\begin{array}{l}0.08 \\
0.15 \\
0.18 \\
0.18 \\
0.26 \\
0.17\end{array}$ & $\begin{array}{l}{[0.05-0.13]} \\
{[0.11-0.21]} \\
{[0.13-0.23]} \\
{[0.14-0.24]} \\
{[0.21-0.33]} \\
{[0.15-0.20]}\end{array}$ & $\begin{array}{l}1.000 \\
1.828 \\
2.235 \\
2.211 \\
3.162 \\
\chi^{2}=20.2, P<0.001\end{array}$ \\
\hline
\end{tabular}

Abbreviations: DM, diabetes; MH-OR, mantel-haenszel-odd ratio; OPD, out patient department. 


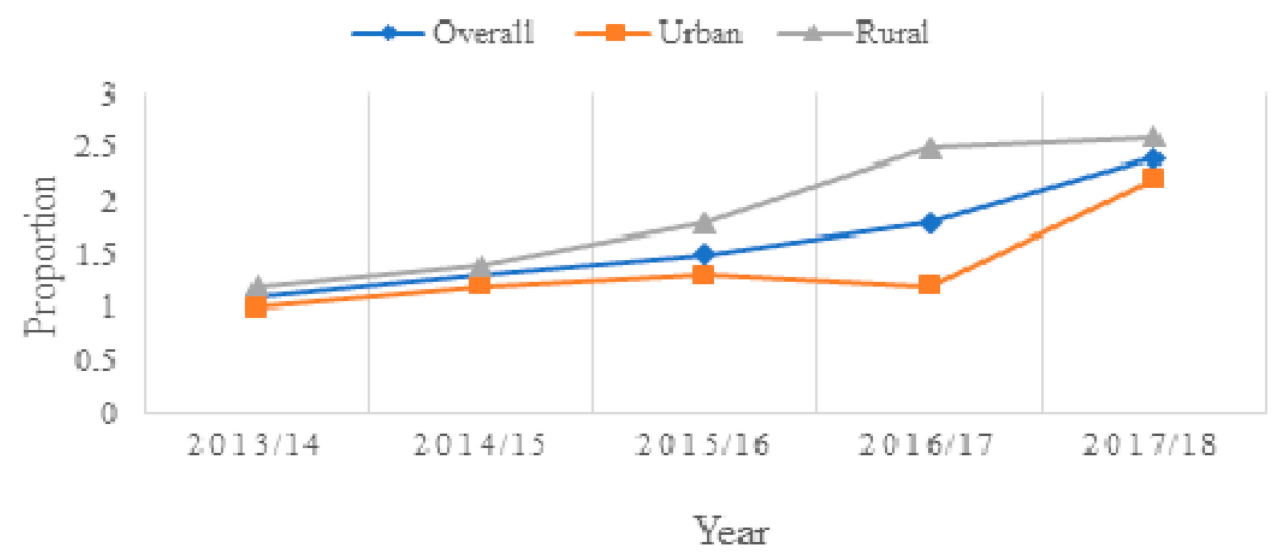

Figure 3 Trends in the proportion of type I diabetes by residence per 1000 adult patients in the selected public hospitals of Tigray, Ethiopia (September I, 2013 to August 31, 2018)

and this is consistent with studies in Ethiopia, Brazil, China, and India. ${ }^{6,24,28,31}$ Therefore, rapid economic and societal transitions, childhood nutritional stunting, chronic undernutrition, improving recording, and diabetes detection mechanisms could lie behind these alarmingly increasing trends of diabetes. ${ }^{17,25}$

Even though the findings of this study showed faster increase in the trend of adult diabetes, the prevalence is lower than from the findings of Ethiopia, Tanzania, Iran, and India. ${ }^{6,22,31,32}$ The discrepancy might be due to differences in the level of urbanization, health literacy, diagnostics criteria, underestimating diabetes for patients with other illnesses. ${ }^{1,25,32}$ The current finding is also much lower compared to the national estimated prevalence of diabetes with $5.2 \%$, which might be due to people die undiagnosed, and about $70 \%$ of people with diabetes do not know that they have diabetes. ${ }^{1}$

This study pointed out the trend in the proportion of adult diabetes has increased among all age groups and most pronounced being with people aged 60 and older years. This finding is in line with similar studies in the US, Sweden, Bulgaria, and Panama, with increasing the trend of diabetes with age over time. ${ }^{4,33-35}$ Aging could impair $\beta$-cell function and impaired $\beta$-cell adaptation to insulin resistance leading to impaired insulin secretion, which might be related to obesity and decreased physical activity. ${ }^{36}$

Studies indicated that diabetes becomes an increasingly prevalent, challenging, and severe public health issue in the 21 st century, for both the urban and rural residents, with the highest prevalence in urbanized regions. ${ }^{1,6,25,27}$ In the current study, even though the trend of adult diabetes is increasing for both urban and rural residents, but the highest proportion observed in urban residents. This study is consistent with studies in Ethiopia, Myanmar, Iran, India, and Kazakhstan. ${ }^{6,22,24,25,37}$ Affluent people live in urban areas, reducing the number of people living in traditional rural livelihoods, which might result in obesity associated with rising living standards. ${ }^{1,6,25,38}$ Likewise, urban life is a more complicated, stressful, and competitive life compared with the rural ones. ${ }^{25,38,39}$ Although the urban population has better access to the healthcare services, including reliable screening methods and diabetes treatment, people die undiagnosed due to lack of health services in rural residents. ${ }^{39}$

A study in the US suggested that type 1 and type 2 diabetes accounted for about $6 \%$ and $91 \%$ of all cases of diagnosed diabetes, respectively. ${ }^{19}$ Recent studies in Italy and Ethiopia indicated, type 1 diabetes is strongly associated with poverty and markers of undernutrition, most marked in the rural cases and excess among men compared to women. ${ }^{17,20,40}$ The trend in the prevalence of T2D is alarmingly increasing over time in developing countries, including SSA countries due to marked economic and epidemiologic transitions, which result in altering lifestyle practices and marked increases in overweight and obesity. ${ }^{21,28,41}$

In several epidemiological studies, T1D in adults is a significant and widespread health problem associated with unacceptably high rates of morbidity and mortality in SSA countries, as a result of childhood nutritional stunting, chronic undernutrition, and environmental factors. ${ }^{17,20,42}$ Although the proportion of T1D in the current study is 1.6 per 1000 adult patients, the potential proportion might be greater than that indicated finding. It might be due to many people die before they are diagnosed and access to diabetes treatment and some type 1 diabetes misclassified as 
Table 3 The Trends of T2D by Residence and Gender (Extended Mantel-Haenszel Chi-Square and Proportion) in Hospitals of Tigray, Ethiopia (September, 2013 to August, 2018)

\begin{tabular}{|c|c|c|c|c|c|c|}
\hline Group of Proportion & Year & $\begin{array}{l}\text { DM } \\
\text { Patients }\end{array}$ & $\begin{array}{l}\text { OPD } \\
\text { Patients }\end{array}$ & $\begin{array}{l}\text { Proportion of DM } \\
\text { (\%) }\end{array}$ & $95 \% \mathrm{Cl}$ & MH-OR \\
\hline Overall & $2013 / 14$ & 317 & 55,734 & 0.57 & {$[0.5 \mathrm{I}-0.63]$} & 1.000 \\
\hline \multirow[t]{5}{*}{ Proportion of T2D } & $2014 / 15$ & 407 & 58,806 & 0.69 & {$[0.63-0.76]$} & 1.216 \\
\hline & $2015 / 16$ & 502 & 60,221 & 0.83 & {$[0.76-0.91]$} & 1.470 \\
\hline & $2016 / 17$ & 593 & 61,805 & 0.96 & {$[0.89-1.00]$} & 1.694 \\
\hline & $2017 / 18$ & 750 & 63,240 & 1.20 & {$[1.10-1.30]$} & 2.098 \\
\hline & Total & 2569 & 299,806 & 0.86 & {$[0.82-0.89]$} & $\chi^{2}=151, P<0.001$ \\
\hline Proportion of T2D Among Urban & $2013 / 14$ & 221 & 31,914 & 0.69 & {$[0.60-0.79]$} & 1.000 \\
\hline \multirow[t]{5}{*}{ Residents } & $2014 / 15$ & 294 & 34,370 & 0.86 & {$[0.77-0.96]$} & 1.237 \\
\hline & $2015 / 16$ & 359 & 34,645 & 1.00 & {$[0.93-1.10]$} & 1.497 \\
\hline & $2016 / 17$ & 402 & 36,244 & 1.10 & {$[1.00-1.20]$} & 1.608 \\
\hline & $2017 / 18$ & 492 & 36,074 & $\mathrm{I} .40$ & {$[1.20-1.50]$} & 1.983 \\
\hline & Total & 1768 & 173,247 & 1.00 & [0.97-1.10] & $\chi^{2}=68.4, P<0.001$ \\
\hline Proportion of T2D Among Rural & $2013 / 14$ & 96 & 23,820 & 0.40 & {$[0.33-0.49]$} & 1.000 \\
\hline \multirow[t]{5}{*}{ Residents } & $2014 / 15$ & 113 & 24,436 & 0.46 & {$[0.38-0.56]$} & 1.148 \\
\hline & $2015 / 16$ & 143 & 25,576 & 0.56 & {$[0.47-0.66]$} & 1.389 \\
\hline & $2016 / 17$ & 191 & 25,561 & 0.75 & {$[0.65-0.86]$} & 1.860 \\
\hline & $2017 / 18$ & 258 & 27,166 & 0.95 & {$[0.84-1.10]$} & 2.369 \\
\hline & Total & 801 & 126,559 & 0.63 & [0.59-0.68] & $\chi^{2}=74.2, \mathrm{P}<0.00 \mathrm{I}$ \\
\hline \multirow[t]{6}{*}{ Proportion of T2D Among Men } & $2013 / 14$ & 184 & 31,312 & 0.59 & {$[0.5 \mathrm{I}-0.68]$} & 1.000 \\
\hline & $2014 / 15$ & 225 & 34,273 & 0.66 & {$[0.58-0.75]$} & 1.118 \\
\hline & $2015 / 16$ & 281 & 34,267 & 0.82 & {$[0.73-0.92]$} & 1.399 \\
\hline & $2016 / 17$ & 351 & 36,579 & 0.96 & {$[0.86-1.10]$} & 1.639 \\
\hline & $2017 / 18$ & 389 & 34,460 & 1.10 & {$[1.10-1.20]$} & 1.932 \\
\hline & Total & 1430 & $|70,89|$ & 0.84 & {$[0.79-0.88]$} & $\chi^{2}=32.0, P<0.001$ \\
\hline \multirow[t]{6}{*}{ Proportion of T2D Among Women } & $2013 / 14$ & 133 & 24,422 & 0.54 & {$[0.46-0.64]$} & 1.000 \\
\hline & $2014 / 15$ & 182 & 24,533 & 0.74 & {$[0.64-0.86]$} & 1.365 \\
\hline & $2015 / 16$ & 221 & 25,952 & 0.85 & {$[0.75-0.97]$} & 1.569 \\
\hline & $2016 / 17$ & 242 & 25,226 & 0.96 & {$[0.85-1.10]$} & 1.769 \\
\hline & $2017 / 18$ & 361 & 28,780 & 1.30 & {$[1.10-1.40]$} & 2.320 \\
\hline & Total & 1139 & 128,915 & 0.88 & {$[0.83-0.94]$} & $\chi^{2}=70.3, P<0.001$ \\
\hline
\end{tabular}

Abbreviations: DM, diabetes; MH-OR, mantel-haenszel-odd ratio; OPD, out patient department.

$\mathrm{T} 2 \mathrm{D} .^{20,42,43}$ The overall trend of type 1 diabetes is increasing in the current study, which is consistent with other studies in the US, Sweden, and SSA countries. ${ }^{18,44,45}$

Different studies suggest that there are major differences in the age and gender of presenting cases together with marked urban-rural variations in the incidence of T1D. ${ }^{17,19,20} \mathrm{We}$ found differences in the proportion of type 1 diabetes between urban and rural areas with almost twofold higher in the rural compared to the urban residents. Type 1 diabetes is strongly associated with poverty and markers of undernutrition most marked in the rural cases, ${ }^{17,46}$ and acute nature of the disease made rural residents seek medical care. ${ }^{47}$ This is inconsistent with studies in Ethiopia urban centers had higher incidence rates than the surrounding rural areas, ${ }^{17}$ which could be due to genetic, environmental, cultural, and socioeconomic variations. Another striking feature of the disease in this study was an excess proportion of T1D in women compared to their men counterparts. It could be due to little attention given to girls in their childhood which lead to undernutrition, genetic susceptibility, and undernutrition at particular times in pregnancy affects many genes that control hepatic and pancreatic function. ${ }^{17,19,20,36}$ This finding is inconsistent with findings in Ethiopia and Italy, where the proportion of type 1 diabetes is excess among men. . $^{17,19,20}$

Even though T2D prevalence is reaching epidemic proportions elsewhere in the world, it is disproportionately 


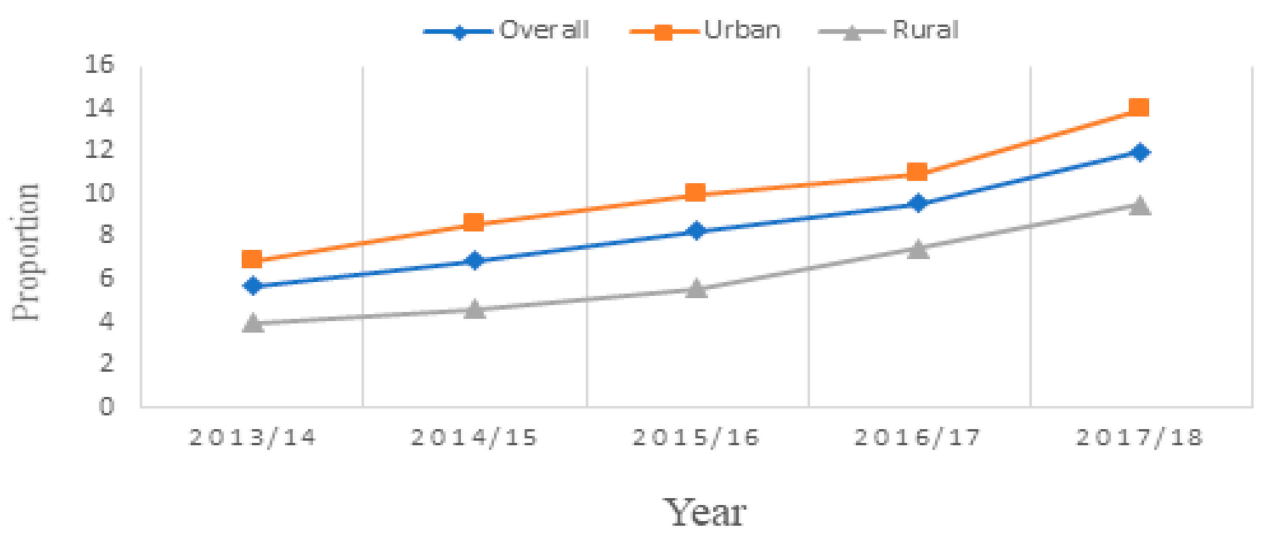

Figure 4 Trends in the proportion of T2D by residence per 1000 adult patients in the selected public hospitals of Tigray, Ethiopia (September I, 20I3 to August 3 I, 20I8).

higher in low-income countries. ${ }^{1,2}$ SSA countries, including Ethiopia, take the lion share in the magnitude of diabetes due to a rapidly epidemiologic and demographic transition. ${ }^{1,6,26}$ In developing countries, the prevalence of T2DM is higher among urban residents compared to their rural counterparts; however, it is higher for rural residents in developed countries. ${ }^{6,25,27}$

The trend of T2DM is increasing with time for both urban and rural residents. In this study, we found a higher proportion of T2DM in an urban resident compared to a rural resident. These marked urban and rural differences in the prevalence of T2DM have reported in other developing countries in India, Bangladesh, and Peru. ${ }^{6,23,48}$ This increase might be due to epidemiologic and demographic transitions, with a sedentary lifestyle and unhealthy diet are still problematic and with a notable increment trend. ${ }^{1,25}$ This study is inconsistent with study in Canada where prevalence of T2DM is higher among rural residents compared to urban residents. ${ }^{27}$

Several studies indicated that the prevalence of T2DM is higher among men compared to women. ${ }^{6,25,49}$ Unlike other studies, we found in this study, women with a higher proportion of T2DM compared to men. This discrepancy could be due to a higher rate of obesity among women compared to their men counterparts ${ }^{29,30}$ and history of gestational diabetes mellitus, which is associated with increased risk of subsequent T2D in mothers. ${ }^{11,28}$

It is imperative to acknowledge, as our results must be viewed in light of several important limitations. The first limitation, the incompleteness of the data in the review charts had some missing data for some variables, which could have led to differences in an unmeasured independent variable for which no correction could be made. The second limitation, data were not validated, which could have led to misclassification of diabetes type. Third, the data were retrospective chart review and underestimate the total number of adults with diabetes, due to some patient charts were lost and not all adult patients who received medical service from the study units were tested for diabetes for those who came for other medical illnesses. The fourth, the study is limited to medical outpatient and emergency units, which do not include obstetrics and surgical units, which might underestimate the proportion of diabetes. Although this finding is not representative of the entire nation, it can generalize for those who are receiving medical services from adult medical outpatient and emergency units of general hospitals of Tigray.

\section{Conclusion}

The overall trend of diabetes is increasing with age over time in the study period. We observed significant increases in the trend of both type 1 and type 2 diabetes among adult patients, for both urban and rural residents steadily with time. A higher proportion of type 1 diabetes is increased in rural residents, and with a statistically significant increase in women study participants, but not in men. Type 2 diabetes has a higher proportion of increase among urban residents, and women participants with time in the observation period.

Our study results might hasten the academia and public interest, resulting in renewed efforts to design effective public health policies. Knowledge about regional prevalence and trend of type 1 and type 2 diabetes in both urban and rural residents might facilitate assessment of the burden of disease and long-term cost-effectiveness of public health interventions and policies aimed at improving diabetes management and help to prioritize regional and national plans for future type-specific health services. 


\section{Acknowledgments}

The sudden death of Professor Fikre Enquo Selassie is extremely painful and hurting. He was not only a good professor of epidemiology and biostatistics but also, he had a unique human entity to his family, students and staff. It pains me to notify you that my supervisor, professor Fikre, left for his heavenly abode on October 28, 2019, on account of sudden death. Professor Fikre was heartily involved in all activities of the study from the proposal development to manuscript approval for publication. The authors express their gratitude to the Addis Ababa University for funding this project. Additionally, we would like to express our heartfelt thanks to the selected public hospitals' administrative bodies, staff, data collectors and supervisors and Tigray Regional Health Bureau office for granting access to these data.

\section{Author Contributions}

All authors contributed from the development of the proposal to data analysis, drafting or revising the article, gave final approval of the version to be published, and agree to be accountable for all aspects of the work. Specifically, GG conceived the idea and developed the study proposal, did the fieldwork, analyzed data, interpreted the findings, and led the manuscript writing. FEQ was involved in proposal development, planning the fieldwork, data analysis and interpretation, manuscript editing and manuscript review. ND and HY were involved in proposal development, planning the fieldwork, data interpretation, manuscript editing, and manuscript review.

\section{Disclosure}

The authors report no conflicts of interest in this work.

\section{References}

1. International Diabetes Federation (IDF). IDF Diabetes Atlas. 8th ed. 2017; 1-150.

2. American Diabetes Association. Standard medical care in diabetes 2018. J Clin Appl Res Edu. 2018;41(1):1-150.

3. World Health Organization. Global Report on Diabetes. Vol. 978; 2016. Isbn.

4. Geiss LS, Wang J, Cheng YJ, et al. Prevalence and incidence trends for diagnosed diabetes among adults aged 20 to 79 years, United States, 1980-2012. J Am Med Assoc. 2014;312(12):1218-1226. doi:10.1001/jama.2014.11494

5. Huber CA, Schwenkglenks M, Rapold R, Reich O. Epidemiology and costs of diabetes mellitus in Switzerland: an analysis of health care claims data, 2006 and 2011. BMC Endocr Disord. 2014;14(44):1-9. doi:10.1186/1472-6823-14-44

6. Satheesh K, Susairaj P. Secular Trends in diabetes in India (STRiDE - I): change in prevalence in 10 years among urban and rural populations in Tamil Nadu. Diabetes Care. 2019;42(March):476-85. doi:10.2337/dc181559
7. Iser BPM, Á V, Duncan BB, Schmidt MI. Trends in the prevalence of self-reported diabetes in Brazilian capital cities and the Federal District, 2006-2014. Diabetol Metab Syndr. 2016;8(1):1-8. doi:10.1186/s13098-016-0185-x

8. Liu X, Yu C, Wang Y, Bi Y, Liu Y, Zhang Z-J. Trends in the incidence and mortality of diabetes in China from 1990 to 2017: a joinpoint and age-period-cohort analysis. Int J Environ Res Public Health. 2019;16(1):158. doi:10.3390/ijerph16010158

9. Who. Global Status Report on Noncommunicable Diseases. World Health Organization; 2014:1-275

10. (NCD-RisC) NRFC. Worldwide trends in diabetes since 1980: a pooled analysis of 751 population-based studies with 4.4 million participants. Lancet. 2016;387(10027):1513-1530. doi:10.1016/ S0140-6736(16)00618-8

11. Kengne AP, Bentham J, Zhou B, et al. Trends in obesity and diabetes across Africa from 1980 to 2014: an analysis of pooled population-based studies. Int J Epidemiol. 2017;46(5):1421-1432. doi:10.1093/ije/dyx078

12. Hailu FB, Hjortdahl P, Moen A. Nurse-led diabetes self-management education improves clinical parameters in Ethiopia. Front Public Health.2018;6(October):1-11.

13. Bedaso A, Oltaye Z, Geja E, Ayalew M. Diabetic ketoacidosis among adult patients with diabetes mellitus admitted to emergency unit of Hawassa university comprehensive specialized hospital. BMC Res Notes. 2019;12(1):1-5.

14. Desse TA, Eshetie TC, Gudina EK. Predictors and treatment outcome of hyperglycemic emergencies at Jimma University Specialized Hospital, southwest. BMC Res Notes. 2015;8(553):1-8. doi:10.1186/ s13104-015-1495-z

15. Abegaz M, Mekonnen GA, Gebreyohannes EA, Gelaye A. Treatment outcome of diabetic ketoacidosis among patients attending general hospital in North-West Ethiopia: hospital based study. BioRxiv. 2018:441964.

16. Xu G, Liu B, Sun Y, et al. Prevalence of diagnosed type 1 and type 2 diabetes among US adults in 2016 and 2017: population based study. BMJ. 2018:362:k1497.

17. Balcha SA, Phillips DI, Trimble ER. Type 1 diabetes in a resourcepoor setting: malnutrition related, malnutrition modified, or just diabetes? Curr Diab Rep. 2018;18(47):2-7.

18. Chiang JL, Kirkman MS, Laffel LMB, Peters AL. Type 1 diabetes through the life span: a position statement of the American Diabetes Association. Diabetes Care. 2014;37(7):2034-2054. doi:10.2337/ dc14-1140

19. Rogers MAM, Kim C, Banerjee T, Lee JM. Fluctuations in the incidence of type 1 diabetes in the United States from 2001 to 2015: a longitudinal study. BMC Med. 2017;15(1):1-9. doi:10.1186/ s12916-017-0958-6

20. Bruno G, Runzo C, Cavallo-Perin P, et al. Incidence of type 1 and type 2 diabetes in adults aged 30-49 years: the population-based registry in the province of Turin, Italy. Diabetes Care. 2005;28 (11):2613-2619. doi:10.2337/diacare.28.11.2613

21. Hall V, Thomsen RW, Henriksen O, Lohse N. Diabetes in Sub Saharan Africa 1999-2011: epidemiology and public health implications. a systematic review. BMC Public Health. 2011;11(1):1-12. doi:10.1186/1471-2458-11-564

22. Veisani Y, Khazaei S, Jenabi E, Delpisheh A. Diabetes mortality and morbidity trends and related risk factors in Iranian adults: an appraisal via current data. J Tehran Univ Hear Cent. 2019;13(2016):2016-2018.

23. Villena JE. Diabetes mellitus in Peru. Ann Glob Health. 2015;81:6.

24. Ambachew Y, Kahsay S, Tesfay R, Tesfahun L, Amare H, Mehari A. Prevalence of diabetes mellitus among patients visiting medical outpatient department of Ayder referral hospital, Mekelle, Ethiopia: a three years pooled. IJPSR. 2015;6(02):435-439.

25. Aung WP, Htet AS, Bjertness E, et al. Urban-rural differences in the prevalence of diabetes mellitus among 25-74-year-old adults of the Yangon Region, Myanmar: two cross-sectional studies. BMJ Open. 2018;1-9. 
26. Ruiz-alejos A, Car RM, Miranda JJ, et al. Addressing the impact of urban exposure on the incidence of type 2 diabetes mellitus: the PERU MIGRANT Study. Sci Rep. 2018;8(1):1-8.

27. Johnson JA, Vermeulen SU, Toth EL, et al. Increasing incidence and prevalence of diabetes among the status aboriginal population in urban and rural Alberta, 1995-2006. Can J Public Heal. 2009;100 (3):231-236. doi:10.1007/BF03405547

28. Hilawe EH, Yatsuya H, Kawaguchi L, Aoyama A. Differences by sex in the prevalence of diabetes mellitus, impaired fasting glycaemia and impaired glucose tolerance in sub-Saharan Africa: a systematic review and meta-analysis. Bull World Health Organ. 2013;91 (9):671-682D. doi:10.2471/BLT.12.113415

29. Darebo T, Mesfin A, Gebremedhin S. Prevalence and factors associated with overweight and obesity among adults in Hawassa City, Southern Ethiopia: a community based cross-sectional study. $B M C$ Obes. 2019;6(1):1-10.

30. Mekonnen T, Animaw W, Seyum Y. Overweight/obesity among adults in North-Western Ethiopia: a community-based cross sectional study. Arch Public Health. 2018;76(1):1-6.

31. Abebe SM, Berhane Y, Worku A, Alemu S. Increasing trends of diabetes mellitus and body weight: a ten year observation at Gondar University Teaching Referral Hospital, Northwest Ethiopia. PLoS One. 2013;8(3):10-13. doi:10.1371/journal.pone.0060081

32. Kinimi E, Balthazary S, Kitua S, Msalika S. Prevalence of diabetes mellitus in patients seeking medical care at Morogoro Regional Referral Hospital in Tanzania. Tanzan J Health Res. 2017;19(4):1-8.

33. Andersson T, Ahlbom A, Carlsson S. Diabetes prevalence in Sweden at present and projections for Year 2050. PLoS One. 2015;10(11):1-10.

34. Borissova A, Shinkov A, Kovatcheva R, Vlahov J, Dakovska L, Todorov T. Changes in the prevalence of diabetes mellitus in Bulgaria (2006-2012). Clin Med Insights Endocrinol Diabetes. 2015;8:41-45. doi:10.4137/CMED.S24742

35. Mc AJ, Posso D, Meza RAB. Diabetes in Panama: epidemiology, risk factors, and clinical management. Ann Glob Heal. 2015;81(6):754764. doi:10.1016/j.aogh.2015.12.014

36. Lee PG, Halter JB. The pathophysiology of hyperglycemia in older adults: clinical considerations. Diabetes Care. 2017;40(4):444-452. doi:10.2337/dc16-1732

37. Supiyev A, Kossumov A, Kassenova A, Nurgozhin T. Diabetes prevalence, awareness and treatment and their correlates in older persons in urban and rural population in the Astana region, Kazakhstan. Diabetes Res Clin Pract. 2016;112:6-12. doi:10.1016/j.diabres.2015.11.011

38. Htet AS, Bjertness MB, Sherpa LY, et al. Urban-rural differences in the prevalence of non-communicable diseases risk factors among 25-74-years-old citizens in Yangon Region, Myanmar: a cross sectional study. BMC Public Health. 2016;16:1-12. doi:10.1186/s12889016-3882-3
39. Kaveeshwar SA, Cornwall J. The current state of diabetes mellitus in India. Australas Med J. 2014;7(1):45-48. doi:10.4066/AMJ.2014. 1979

40. Fekadu S, Yigzaw M, Alemu S, et al. Insulin-requiring diabetes in Ethiopia: associations with poverty, early undernutrition and anthropometric disproportion. Eur J Clin Nutr. 2010;64(10):1192-1198. doi:10.1038/ejen.2010.143

41. Ajayi IO, Adebamowo C, Adami H, et al. Urban-rural and geographic differences in overweight and obesity in four sub-Saharan African adult populations: a multi-country cross-sectional study. BMC Public Health. 2016;16(1):1-13.

42. Diaz-Valencia PA, Bougnères P, Valleron AJ. Global epidemiology of type 1 diabetes in young adults and adults: a systematic review. $B M C$ Public Health. 2015;15(1). doi:10.1186/s12889-015-1591-y

43. Bullard KM, Cowie CC, Lessem SE, et al. Morbidity and mortality weekly report prevalence of diagnosed diabetes in adults by diabetes type - United States, 2016. Morb Mortal Wkly Rep. 2016;67 (12):2016-2018

44. Majaliwa ES, Elusiyan BEJ, Adesiyun OO, et al. Type 1 diabetes mellitus in the African population: diabetes care. Acta Biomed. 2008;30(9):255-259.

45. Hussen HI, Persson M, Moradi T. The trends and the risk of type 1 diabetes over the past 40 years: an analysis by birth cohorts and by parental migration background in Sweden. BMJ Open. 2013;3:10. doi:10.1136/bmjopen-2013-003418

46. World Food Program and Central Statistical Agency of Ethiopia: Comprehensive Food Secruity and Vulnerability Analysis, Ethiopia, Addis Ababa, 2019.

47. Asfaw LS, Ayanto SY, Aweke YH. Health-seeking behavior and associated factors among community in Southern Ethiopia: community based cross-sectional study guided by health belief model. $B M C$ Pregnancy Childbirth. 2018;12(74):1-24.

48. Alam DS, Talukder SH, Chowdhury MAH, et al. Overweight and abdominal obesity as determinants of undiagnosed diabetes and prediabetes in Bangladesh. BMC Obes. 2016;3:1. doi:10.1186/s40608016-0099-z

49. Sharma M, Nazareth I, Petersen I. Trends in incidence, prevalence and prescribing in type 2 diabetes mellitus between 2000 and 2013 in primary care: a retrospective cohort study. BMJ Open. 2016;6(1):1-9. doi:10.1136/bmjopen-2015-010210

\section{Publish your work in this journal}

Diabetes, Metabolic Syndrome and Obesity: Targets and Therapy is an international, peer-reviewed open-access journal committed to the rapid publication of the latest laboratory and clinical findings in the fields of diabetes, metabolic syndrome and obesity research. Original research, review, case reports, hypothesis formation, expert opinion and commentaries are all considered for publication. The manuscript management system is completely online and includes a very quick and fair peer-review system, which is all easy to use. Visit http://www.dovepress.com/testimonials.php to read real quotes from published authors. 